\title{
The Need for the Establishment of Biomedical Engineering as an Academic and Professional Discipline in the Philippines - A Quantitative Argument
}

\author{
Jamie Ledesma Fermin ${ }^{1} \ddagger$, Student Member, IEEE, and Myles Joshua Toledo $\operatorname{Tan}^{2,3} \ddagger$, Member, IEEE \\ $\dashv$ Equal Contribution \\ ${ }^{i}$ Department of Electronics Engineering, University of St. La Salle, Bacolod City, Philippines \\ ${ }^{2}$ Department of Natural Sciences, University of St. La Salle, Bacolod City, Philippines \\ ${ }^{3}$ Department of Chemical Engineering, University of St. La Salle, Bacolod City, Philippines \\ Corresponding Author: Myles Joshua Toledo Tan (mj.tan@usls.edu.ph)
}

The authors received no specific funding for this work.

ABSTRACT Background: This article quantitatively presents the relationship between volume of BME publications produced from 1990 to 2019 in the member states of the ASEAN and 12 indicators of overall and physical health. The objective was to show that ASEAN states that recognize BME as an academic and professional discipline have been successful in producing research in the field, and thus, have advanced the provision of high-quality healthcare for their people.

Results: Acceptable relationships [Pearson correlation coefficients $(\mathrm{PCC})>0.6000$ ] were found between BME publication volume and all indicators. Stronger relationships $(\mathrm{PCC}>0.7000)$ were found between BME publication volume and the natural logarithm of the indicators. Brunei data behaved anomalously and was removed to check for any improvements in PCC. Indeed, PCCs for all indicators improved significantly upon exclusion of Brunei data [PCC $>0.8000$ for six indicators (linear scale), PCC $>0.9000$ for five indicators (log scale)]. These PCCs signify especially strong relationships between BME research yield and healthcare quality in a country. To visualize the relationships, BME publication volume was plotted against GDP per capita, while the remaining 11 indicators were each plotted against BME publication volume. Linear, logarithmic, and exponential regression curves were overlaid on the datapoints. Coefficients of determination $\left(\mathrm{R}^{2}\right)$ were calculated to measure the aptness of the fits. $\mathrm{R}^{2}>0.9000$ for two indicators, $\mathrm{R}^{2}>$ 0.8000 for five indicators, $\mathrm{R}^{2}>0.7000$ for four indicators, and $\mathrm{R}^{2}<0.7000$ for only one indicator were calculated from the curve fits overlaid on the datapoints excluding Brunei data.

Conclusion: We believe that it is time for the Philippines to adopt BME as an academic and professional discipline, so that it may one day enjoy the benefits brought about by advancements in the provision of healthcare, which are experienced by its neighbors that have gone ahead with movements to cultivate the highly essential discipline.

INDEX TERMS biomedical engineering, BME, healthcare engineering, healthcare, Philippines, ASEAN

\section{INTRODUCTION}

Technology has become an inseparable aspect of human life and has transmogrified how people interact with the world and with each other. It is undeniable that virtually everything that we do today is done with the aid of technology. For people to function effectively in today's society, it is imperative that they possess the requisite knowledge and skills to wield the technology of today as leverage in order to improve the environment and quality of life for all. Moreover, a consequently parallel progress in technology 
seems to emerge because of the ever-growing demand for superior-quality healthcare.

As a result, more and more opportunities for the creation of devices in the medical field to solve everyday problems grow alongside this progress. Thus, technological advancements seen over the past decades have been an integral part in the development of healthcare systems. Further progress in science and technology drives the increase in life expectancy through improvements seen in the provision of quality healthcare. For instance, between the years 1900 and 2000, life expectancy at birth was observed to have increased by 63 percent in the United States, from 47.3 years to 77.0 years [1]. Moreover, numerous authors have claimed that much of the recent gains in life expectancy are primarily due to biomedical research and innovation [2] - [4].

Biomedical engineering (BME), also referred to as bioengineering, is a discipline that combines various principles of medicine and biology to formulate innovative medical technologies that would drive the betterment of healthcare systems [5], [6]. This discipline aims to close the gap between engineering and biomedicine in order to fulfill the very goal of technology, as earlier asserted — to improve the environment and to improve the quality of life for all. Biomedical engineering formally became an academic discipline during the 1950s at universities in the United States, such as the University of California Berkeley, the University of California San Francisco, the University of Pennsylvania, and Drexel University [7]. Because of the emergence of this discipline, engineering professionals have frequently involved themselves in many endeavors to enhance biomedicine [8]. For this reason, biomedical engineering has paved the way for engineers and medical professionals to come together and solve pressing health issues by designing medical devices that incorporate biosensors, biomaterials, image processing, artificial intelligence, and similar technologies that can be used to diagnose and treat disease [8]. Since biomedical engineering encompasses a myriad of principles adopted from other disciplines such as electrical engineering, chemical engineering, mechanical engineering, physics, chemistry, and biology, the opportunities for collaboration between engineers and healthcare professionals are many and varied [8].

According to the International Standard Classification of Occupations (ISCO-08) by the International Labour Organization (ILO) and Global strategy on human resources for health: Workforce 2030 by the World Health Organization (WHO), biomedical engineering professionals and biomedical engineering technicians are now considered to be integral in the health workforce [9] - [11]. In recent years, the WHO documented a significant increase in the presence of biomedical engineering professionals in 126 of 194 WHO member states. The total number of biomedical engineers identified across 129 of the 194 WHO member states was found to be 117,935 in the year 2015. It is also essential to consider that these 129 states include low- and middle-income member states with small yet advancing biomedical engineering labor forces [10].

In 1963, the first BME academic program in Asia was established through the initiative of Japan [10]. Subsequently, in the Association of Southeast Asian Nations (ASEAN), the faculty of engineering at the University of Malaya (UM) was the first to establish its academic program in BME in 1997, making it the first of its kind in Malaysia [12], [13]. This movement was then followed by the National University of Singapore (NUS) in 2001 when the faculty of engineering of NUS began to offer its Minor in Bioengineering program. The succeeding year (2002), the Division of Bioengineering was officially formed at NUS [14]. In 2004, Indonesia began to offer its first formal academic program in BME - a movement that was led by the Bandung Institute of Technology [10], [15]. According to the Biomedical Engineering Society in Vietnam (BMES-VN), the Ho Chi Minh City International University of the Vietnam National University System was the first university in Vietnam to open an accredited bachelor of engineering degree program in BME in 2009 [16]. Fairly recently in 2019, a movement to develop a BME program in Cambodia was initiated. The movement is a collaboration between experts from the Faculty of Biomedical Engineering at the Czech Technical University in Prague, the Cambodian University of Health Sciences, and the Cambodian Institute of Technology [17]. At the moment, there are no degree programs in BME offered in any of the institutions of higher education in the Philippines yet. However, the bachelor of science program in Manufacturing Engineering and Management (MEM) at the De La Salle University offers a specialization in BME. Moreover, the University has drafted plans to offer its Bachelor of Science program in BME in academic year 2021 - 2022, which would be the first undergraduate BME program in the country [18].

In this study, we sought to establish a correlation between the quantity of biomedical engineering research publications and the advancement of healthcare systems in ASEAN nations. By establishing these correlations, we could postulate the relationship between BME research, and the amount of attention given to healthcare by governments and by learned institutions (e.g. universities, research centers, hospitals, and learned societies). If adequate attention and focus are granted to healthcare, more funding will consequently be channeled toward biomedical research, and greater efforts will be carried out to improve healthcare policy. These two (development of biomedical technology and development of healthcare policy) are effects of the same cause - increased attention and focus toward healthcare. However, a more profound relationship exists between these two. Biomedical research could potentially drive forward healthcare policy, and healthcare policy could potentially drive forward biomedical research. Hence, from this, we 
could further postulate a positive feedback relationship between advancement in BME research and improvement in healthcare. Finally, we hope for people, especially engineering professionals and makers of technological policy, to realize that anyone trained in any of the engineering disciplines, be it electrical, chemical, mechanical (or really any discipline) is capable of contributing to the field of medicine and to the amelioration of Philippine healthcare.

\section{METHODS}

For this study, we chose to evaluate the member states of the ASEAN, which is an intergovernmental organization that comprises 10 nations in Southeast Asia - Brunei Darussalam, Cambodia, Indonesia, Laos, Malaysia, Myanmar, the Philippines, Singapore, Thailand, and Vietnam. Although sociocultural characteristics and levels of economic development vary greatly among ASEAN member states [19], the development aspirations of the ASEAN bring member states together as they aid each other in pursuit of economic, political, security, military, educational, and sociocultural reforms. The choice of indicators, which are later enumerated, therefore, form good quantifiable metrics to evaluate the quality of healthcare in the member states of this geographic bloc. Despite the socioeconomic differences among ASEAN member states, this intergovernmental organization provides support for them whenever needs arise. Moreover, because of the geographic proximity of the ASEAN nations to each other, the organization is able to facilitate regional collaboration and innovation. This allows ASEAN states to work toward replicating developments that are seen in Singapore and toward normalizing the quality of healthcare enjoyed by Singapore all throughout the ASEAN.

Organization-owned data repositories, such as those by the World Bank [20], the World Health Organization [21], the SCImago Journal Rank (SJR) [22], the Institute for Health Metrics and Evaluation (IHME) [23], the United Nations Development Programme (UNDP) [24], and The Lancet [25] were utilized to collect the necessary data. The data from these sources were either manually extracted and recorded in a comma separated values (CSV) file, or downloaded directly as a CSV file.

The volumes of BME publications produced between 1990 and 2019, which were taken from the SJR data repository, were chosen to be the metric for how active BME research has been in each of the ASEAN member states. SJR was chosen over other citation-based research analytics tools, such as Journal Citation Reports ${ }^{\mathrm{TM}}$, because it is an open access resource that contains a large collection of journals originating from a greater variety of countries. Moreover, it is worth mentioning that SJR includes journals that were written in languages other than English [26]. The correlation between this cumulative publication yield and each of the 12 indicators for the state of healthcare was then calculated for each ASEAN member state. The 12 indicators that were chosen were the following: Gross Domestic Product (GDP) per capita, Human Development Index (HDI) value, Healthcare Access and Quality (HAQ) index, Life Expectancy at Birth, Healthy Life Expectancy at Birth, Maternal Mortality Ratio (MMR), Neonatal Mortality Rate (NMR), Probability of Dying from Noncommunicable Diseases (NCDs), and rates of mortality due to Stroke, Diabetes Mellitus, Congenital Birth Defects, and Leukemia. The GDP per capita data for ASEAN nations were collected from the World Bank data repository [20] and were then used to analyze whether economic prosperity has any quantifiable relationship with the volume of BME publications in each country.

The UNDP data for HDI was compared with the number of BME publications. HDI value is a good indicator for health because it reflects all five dimensions of personal health physical, emotional, social, spiritual, and intellectual. The HDI measures three key elements in human development health, education, and income. The health element is determined by the number of years lived by an individual. The education element, on the other hand, is determined by the mean number of years of education received by adults aged 25 years and older, and the expected number of years that would be spent by children entering school that year. Finally, the income element is determined using the gross national income (GNI) per capita of a country. HDI is then calculated as the geometric mean of the normalized values for each of the three elements and is reported as a quantity between 0.000 and 1.000 [27].

The HAQ Index, which was taken from the IHME, is a robust and comprehensive indicator of healthcare in a country because it is a measure of both access to and quality of healthcare in a given location. Life expectancy at birth is defined as the average number of years that people in a country are expected to live, while healthy life expectancy at birth considers both mortality data and health status to estimate the number of years lived by individuals in a population that are spent in good health [28]. Both these sets of data were collected from World Health Statistics 2020 by the WHO [21]. These two form powerful indicators of health because a rise in life expectancy at birth and healthy life expectancy at birth can be equated with an improvement in living standards, an enhancement in manner of life, and better access to good quality healthcare services.

Furthermore, the data for MMR, NMR, and probability of dying from NCDs were also collected from the World Health Statistics report [21]. Maternal mortality is defined as "the death of a woman while pregnant or within 42 days of termination of pregnancy, irrespective of the duration and site of the pregnancy, from any cause related to or aggravated by the pregnancy or its management but not from accidental or incidental causes" [29]. It is measured for every 100,000 live births [21] and is considered to be a good indicator for healthcare because it uncovers the magnitude of pregnancy- 
related conditions, close calls, potentially fatal outcomes after birth, and long-term consequences that affect the wellbeing of the mother [30]. Neonatal mortality, on the other hand, is defined as the death of newborns within the first 28 days of life and is measured in terms of deaths for every 1,000 live births. NMR is a strong indicator for the quality of healthcare because a high NMR is generally indicative of unrealized needs for sanitation, nutrition, and healthcare among newborns.

Another measure for the quality of healthcare in a country is the probability of dying from NCDs. An NCD is any chronic disease that is not transmissible. Although also classified as NCDs, mortality rate data for diabetes mellitus, and leukemia were separately collected from The Lancet, while mortality data for stroke was collected from the IHME data repository to quantify outcomes of healthcare provided to the infirm. Stroke occurs when oxygen is unable to reach the brain due to an interruption in blood flow (ischemic) or when rupture of a blood vessel in the brain causes a bleed (hemorrhagic). Patients with diabetes mellitus, on the other hand, suffer from the effects of high levels of blood sugar that result from either the lack of insulin inside the body (type 1) or faulty interactions between insulin and its receptors (type 2). Additionally, leukemia is a type of cancer that affects the blood and is characterized by an abnormal rise in white blood cells in the body. When the probability of dying from NCDs is low, the existence of effective healthcare interventions could be implied. Moreover, if the life of a patient is prolonged after diagnosis, i.e. if prognosis is good, it would mean that healthcare in a country is of favorable quality.

Finally, a congenital birth defect is defined as any structural or functional anomaly that manifests at birth and that could render a person disabled. Because these conditions are present from the time of birth, life expectancy is affected. Furthermore, if a person born with a congenital defect exceeds the life expectancy or at least achieves the average life expectancy, this could be a good indicator of improvements in nutrition and healthcare.

After the data collection process, Python $\AA$ and Microsoft $\AA$ Excel ${ }^{\circledR}$ were used for data manipulation and data analysis. Pandas, a built-in library in Python $\AA$, was used to build DataFrames that stored the collected publication yield data and indicator values. Also, Matplotlib, a plotting library, was used to create graphs for data visualization. A numerical library called NumPy (i.e. Numerical Python) was also used to calculate the natural logarithms of the indicator values.

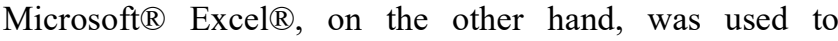
determine the equation of the best fit curve and the coefficients of determination $\left(\mathrm{R}^{2}\right)$ for each graph. The graph of the best fit curve was then overlaid on the datapoints and III. RESULTS

Here, all results derived from the analyses that were described in the METHODS section are summarized and presented. the $\mathrm{R}^{2}$ was used as a statistical measure to determine how closely the data "obeyed" the regression curve. However, data from Brunei exhibited anomalous behavior, which did not conform with the trend established through the data collected from its nine ASEAN neighbors. It was then decided that data from Brunei would be excluded in order to observe what might happen to the Pearson correlation coefficient (PCC) values and $\mathrm{R}^{2}$ scores. The means and standard deviations (SD) of BME publication yield and the indicators were also calculated using the Microsoft ${ }^{\circledR}$ Excel ${ }^{\circledR}$ to determine the central tendencies of the values from the ASEAN region and how spread the indicator values are from each other.

Within the contexts of this article, a quantity is considered to be significantly above the mean if the value is greater than one SD above the mean, and significantly below the mean if the value is greater than one SD below the mean. The PCC was used to quantify the linear relationship between BME publication yield and indicator values or the natural logarithms thereof. A PCC of 0.6000 was considered to be acceptable. However, a PCC of at least 0.8000 was needed for a relationship to be considered strong. When the PCC between BME publication volume and the natural logarithm of the indicator value was found to be greater than the PCC between BME publication volume and the indicator itself, then the BME publication volume was said to be optimally correlated with the natural logarithm of the indicator. However, when the PCC between BME publication volume and the indicator was found to be greater than the PCC between BME publication volume and the natural logarithm of the indicator, then the BME publication volume was said to be optimally correlated with the value of the indicator itself. Thus, optimal PCC was defined to be the highest recorded PCC for the indicator, which happened to uniformly be a case that excluded Brunei data. 
Table I: Cumulative BME publication yield from 1990 to 2019 and selected socioeconomic indicators that capture the overall wellbeing and health of populations in the ASEAN.

\begin{tabular}{|c|c|c|c|c|c|c|}
\hline Philippines & 195 & 3485 & 0.712 & 51.2 & 69.3 & 61.7 \\
\hline Mean & 1511 & 13146 & 0.723 & 57.8 & 72.7 & 64.5 \\
\hline Laos & 4 & 2535 & 0.604 & 36.6 & 65.8 & 57.9 \\
\hline Cambodia & 7 & 1643 & 0.581 & 39.4 & 69.4 & 60.8 \\
\hline Myanmar & 16 & 1408 & 0.584 & 41.6 & 66.8 & 58.4 \\
\hline Brunei & 41 & 31087 & 0.845 & 76.4 & 76.4 & 67.9 \\
\hline Vietnam & 807 & 2715 & 0.693 & 60.3 & 76.3 & 67.5 \\
\hline Indonesia & 1037 & 4136 & 0.707 & 44.5 & 69.3 & 61.7 \\
\hline Thailand & 2057 & 7808 & 0.765 & 69.5 & 75.5 & 66.8 \\
\hline Malaysia & 4471 & 11415 & 0.804 & 68.1 & 75.3 & 66.6 \\
\hline Singapore & 6476 & 65233 & 0.935 & 90.6 & 82.9 & 76.2 \\
\hline
\end{tabular}

a Volume of Biomedical Engineering Publications, 1990-2019 [22]

${ }^{b}$ Gross Domestic Product per capita, in USD, 2019 [20]

c Human Development Index value, 2019 [24]

d Healthcare Access and Quality Index, 2016 [23]

e Life Expectancy at Birth in years, 2016 [21]

${ }^{\mathrm{f}}$ Healthy Life Expectancy at Birth in years, 2016 [21]

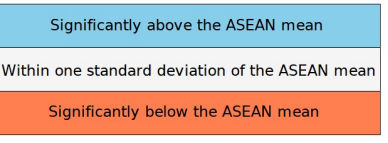

Table II: Incidence of mortality due to diseases selected as indicators for quality of healthcare in the ASEAN

9 Maternal Mortality Ratio for every 100,000 live births, 2017 [21]

h Neonatal Mortality Rate for every 1,000 live births, 2018 [21]

i Probability of Dying from NCDs between ages 30 to 69, in percent, 2016 [21]

${ }^{j}$ Incidence of Deaths due to Stroke for every 100,000 population, 2017 [23]

$\mathrm{k}$ Incidence of Deaths due to Diabetes Mellitus for every 100,000 population, 2017 [25]

I Incidence of Deaths due to Congenital Birth Defects for every 100,000 population, 2017 [25]

$\mathrm{m}$ Incidence of Deaths due to Leukemia for every 100,000 population, 2017 [25 

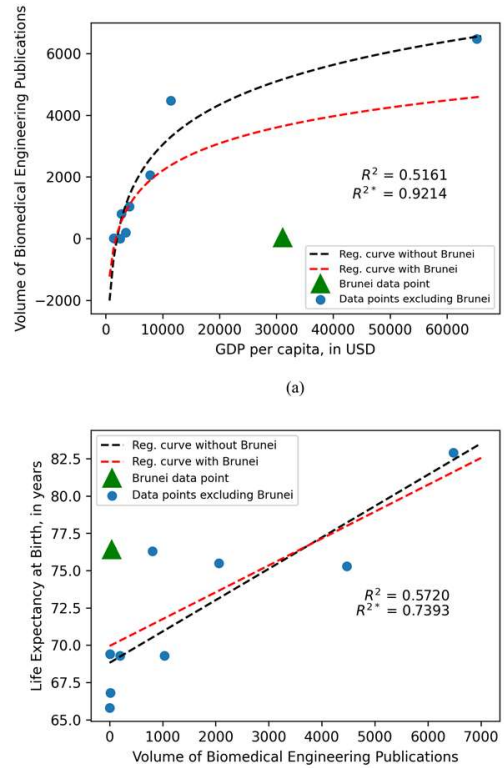

(d)

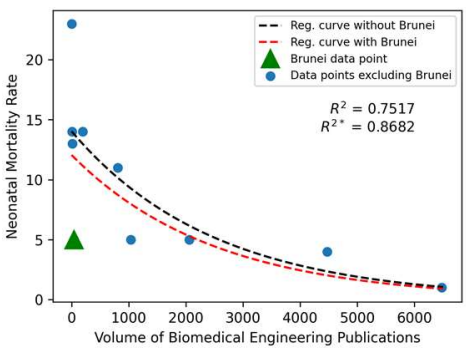

(g)

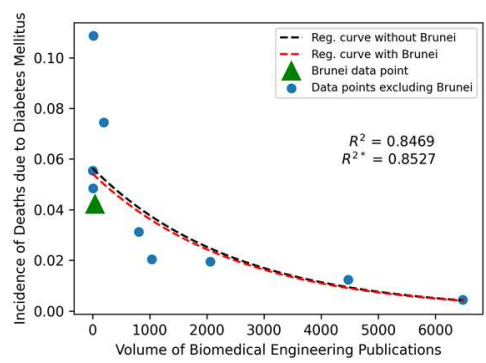

(j)
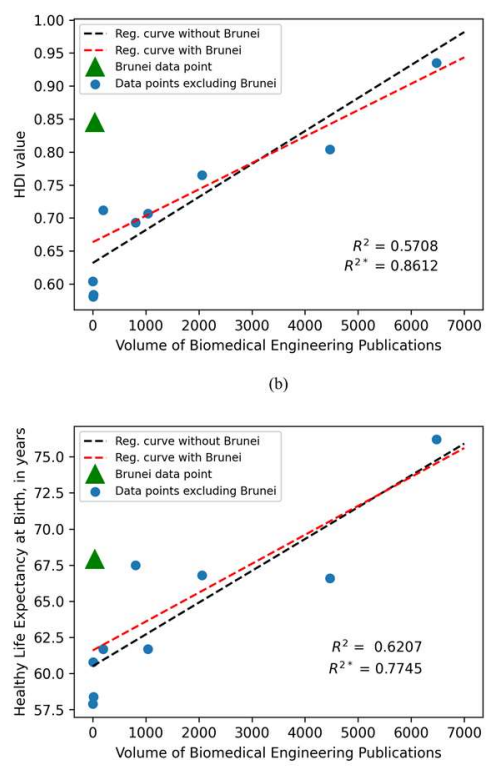

(e)

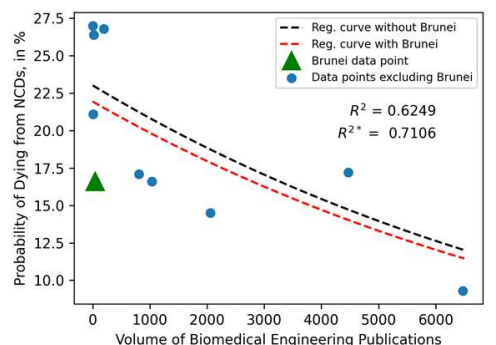

(h)

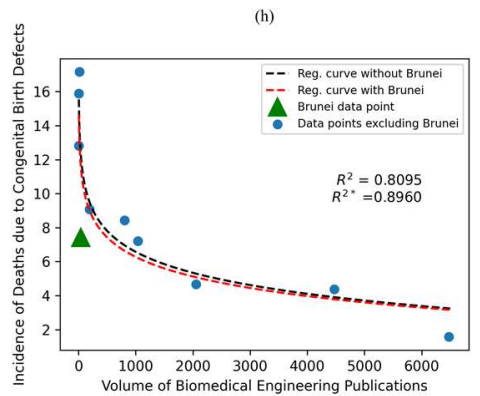

(k)
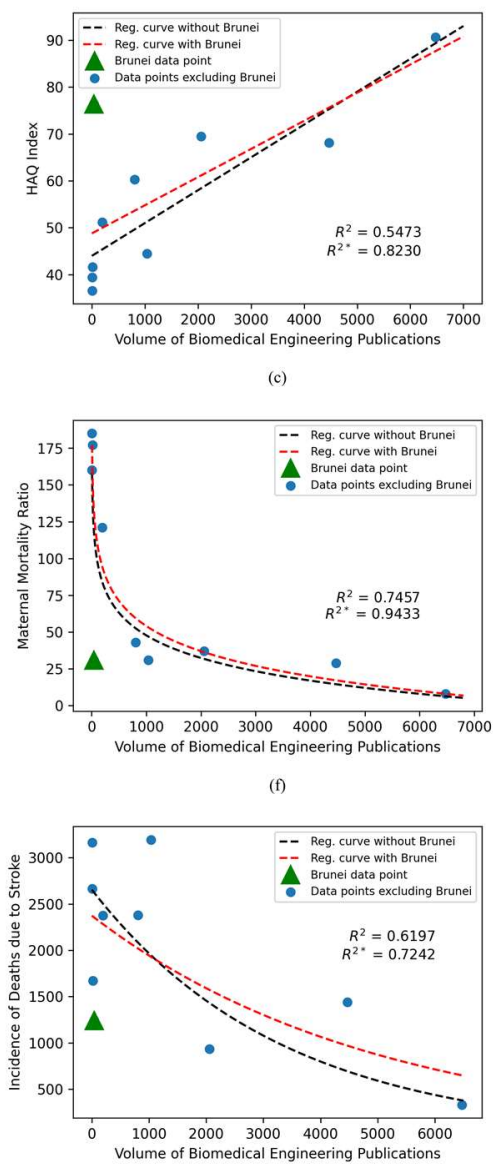

(i)

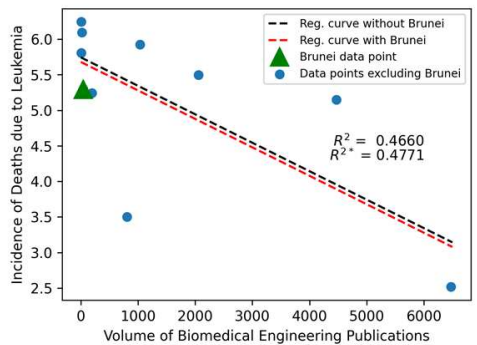

(1)

Figure 1. Scatter plots with best curve fits of (a) volume of biomedical engineering publications against GDP per capita in USD, logarithmic curve fit with $R^{2}=0.5161, R^{2 *}=$ 0.9214; (b) HDI value against volume of biomedical engineering publications, linear fit with $R^{2}=0.5708, R^{2^{*}}=0.8612$; (c) $H A Q$ index against volume of biomedical engineering publications, linear fit with $R^{2}=0.5473, R^{2^{*}}=0.8230$; (d) life expectancy at birth in years against volume of biomedical engineering publications, linear fit with $R^{2}=0.5720, R^{2^{*}}=0.7393$; (e) healthy life expectancy at birth in years against volume of biomedical engineering publications, linear fit with $R^{2}=0.6207, R^{*}=0.7745 ;(f)$ maternal mortality ratio for every 100,000 live births against volume of biomedical engineering publications, logarithmic curve fit with $R^{2}=0.7457$, $R^{2^{*}}=0.9433$; $(g)$ neonatal mortality rate for every 1,000 live births against volume of biomedical engineering publications, exponential curve fit with $R^{2}=0.7517, R^{2 *}=0.8682 ;(h)$ probability of dying from NCDs between ages 30 to 69 in \% against volume of biomedical engineering publications, exponential curve fit with $R^{2}=0.6249$, $R^{2^{*}}=0.7106$; (i) incidence of deaths due to stroke for every 100,000 population against volume of biomedical engineering publications, exponential curve fit with $R^{2}=0.6197, R^{2^{*}}=0.7242 ;(j)$ incidence of deaths due to diabetes mellitus for every 100,000 population against volume of biomedical engineering publications, exponential curve fit with $R^{2}=0.8469$, $R^{2 *}$ $=0.8527$; (k) incidence of deaths due to congenital birth defects for every 100,000 population, logarithmic curve fit with $R 2=0.8095, R^{2^{*}}=0.8960 ;(I)$ incidence of deaths due to leukemia for every 100,000 populations against volume of biomedical engineering publications, linear fit with $R^{2}=0.4660, R^{2 *}=0.4771$. $R^{2}$ specifies the coefficient of determination for the regression curve fitted to the datapoints that include Brunei data, while $\mathrm{R}^{2^{*}}$ specifies the coefficient of determination for the regression curve fitted to the datapoints that exclude Brunei data. 
Table III: Pearson correlation coefficients (PCCs) between volume of biomedical engineering publications and the 12 indicators for healthcare and their respective natural logarithms; and PCCs between the same pairs of variables but excluding Brunei data.

\begin{tabular}{|c|c|c|c|c|}
\hline Indicator, I & $\mathrm{PCC}[\mathrm{I}, \mathrm{N}]$ & $\mathrm{PCC}[\ln \mathrm{I}, \mathrm{N}]$ & $\begin{array}{l}\text { PCC[I, N] } \\
\text { without Brunei }\end{array}$ & $\begin{array}{c}\mathrm{PCC}[\ln \mathrm{I}, \mathrm{N}] \\
\text { without Brunei }\end{array}$ \\
\hline HDI & +0.7555 & +0.7338 & +0.9279 & +0.9042 \\
\hline HAQ Index & +0.7398 & +0.7051 & +0.9072 & +0.8707 \\
\hline GDP per capita & +0.7297 & +0.7184 & +0.8659 & +0.9599 \\
\hline Life Expectancy at Birth & +0.7563 & +0.7452 & +0.8598 & +0.8519 \\
\hline Healthy Life Expectancy at Birth & +0.7879 & +0.7754 & +0.8800 & +0.8726 \\
\hline Maternal Mortality Ratio & -0.6286 & -0.7985 & -0.7313 & -0.8822 \\
\hline Neonatal Mortality Rate & -0.6810 & -0.7286 & -0.7783 & -0.9318 \\
\hline Probability of Dying from NCDs & -0.7245 & -0.7905 & -0.7919 & -0.8430 \\
\hline Stroke & -0.6683 & -0.7872 & -0.7726 & -0.8510 \\
\hline Diabetes Mellitus & -0.6893 & -0.9203 & -0.7072 & -0.9234 \\
\hline Congenital Birth Defects & -0.7645 & -0.9149 & -0.8133 & -0.9390 \\
\hline Leukemia & -0.6827 & -0.7039 & -0.6907 & -0.7069 \\
\hline
\end{tabular}

\section{DISCUSSION}

\section{A. The Human Development Index and Life Expectancy} According to Table I, countries such as Laos, Cambodia, and Myanmar have HDI values that are at least one standard deviation below the mean HDI value of ASEAN member states. This implies that they are relatively underdeveloped compared to other ASEAN countries in terms of longevity, provision of education, and economic status. Moreover, the average lifespan in Laos of 65.8 years is greater than one standard deviation less than that of a typical ASEAN country. A similar case is observed in Myanmar where the average length of life is 66.8 years. Human ageing is an inevitable phenomenon that brings about deterioration in every facet of a person's wellbeing [31]. It is estimated that the elderly population, i.e. the number of individuals aged 60 or greater, would increase to 1.2 billion in the year 2025 and would eventually grow to two billion in the succeeding 25 years [32]. It was observed in the last century that there has been a continuous rise in the average life expectancy in most countries without any indication of saturation [31]. The observed natural process could be the effect of efforts that have been put in place to ameliorate the quality of life of populations. The elderly is more prone to morbidity because of functional impairments to the immune system that undermine their abilities to combat disease. As an aggravating consequence, complications ensue [33] - [35]. Moreover, the ageing process is associated with the loss of tissue and organ function over time. Due to advanced age, elderly individuals suffer from high levels of oxidative stress. As a result, cardiovascular, cellular repair, metabolic, and neurological functionalities decline. This renders elderly individuals more susceptible to cardiovascular disease (CVD), cancer, diabetes mellitus, and neurodegenerative disorders, such as Alzheimer's and Parkinson's [36].
The most recent rise in life expectancy among countries that already have low rates of mortality is associated with the decline in mortality among the elderly population [37]. As the overall state of health increases, the elderly population grows, as well [38]. In Table I, a notable distinction between life expectancy at birth and healthy life expectancy at birth can be found. It is expected that individuals who are healthy will live longer than those who are frail [39]. Hence, for countries such as Laos and Myanmar whose people live lives that are significantly shorter than the ASEAN mean, the overall length of life is significantly greater than the number of years lived in good health by a person. The large disparity between life expectancy and healthy life expectancy would render a person a financial burden to his/her family and an economic burden to his/her country. While the ageing population soars as time progresses, a corresponding increase in demand for better quality geriatric and potentially palliative healthcare arises. We are aware that the elderly tends to be more infirm and thus, requires a great amount of resources, such as long-term care services and special medical attention compared with other age groups [40], [41].These resources are costly and without any assistance from the government or any health insurance coverage, healthcare access would be difficult to obtain, if not unreachable [42]. For elderly individuals to maintain good health, they must either observe a healthy lifestyle or undergo regular medical checkups. However, because of the development of healthcare, the associated costs also increase. Moreover, these costs give rise to greater economic burdens in the lives of elderly individuals and their families [43]. The financial resources (e.g. retirement fund) of an elderly individual, who needs long-term care and is not covered by insurance, would rapidly be depleted [44], [45]. When this happens, he/she would lose his/her financial independence and would have to rely on the financial capabilities of his/her children and relatives to support his/her needs. 


\section{B. Rehabilitation engineering}

A specialized branch of BME, called rehabilitation engineering, aims to ameliorate the quality of life of ageing and physically impaired populations. Engineers in this discipline combine medicine and engineering to create innovative devices that could assist and facilitate the functionality of individuals with physical impairments [46], [47]. The Rehabilitation Act of 1973 of the United States encourages efforts to support Rehabilitation Research Centers in the development of innovative methods for the application of medical technology to the rehabilitation of the physically handicapped [47] - [50]. As of 2019, the government of the United States has made sustained efforts and commitments to augment the quality of life of persons with disabilities (PWDs). Moreover, the United States government has allocated a total of USD 3.6 billion to support Vocational Rehabilitation (VR) services and programs for physically handicapped individuals to train and prepare them to live functional lives in the community [51]. In the year 2012, Asia's first assistive technology and rehabilitation engineering event was launched in Singapore, Asia's medical hub. The event promoted the vast capabilities and arrays of possibilities for medical technology to support and to restore the quality of life of the disabled and aged [52]. In low- and middle-income countries, such as the Philippines, rehabilitation outcomes are poor because of the inadequate access to rehabilitation technologies, services, and skilled clinicians. However, with the help of existing affordable biomedical engineering-based assistive technologies, rehabilitation approaches could be improved and subsequently used to ameliorate the conditions of the disabled in the country. The low-cost design of technologies such as interactive game interfaces that employ hand exoskeleton devices [53], robot-mediated therapies [54], and therapies aided by commercial video game systems [55], could potentially increase accessibility to physical rehabilitation for lower- and middle-income patients in the Philippines and thus, could facilitate the integration of biomedical engineering-based technologies in rehabilitation centers in the Philippines.

\section{Accessibility of healthcare through telemedicine channels}

In Table I, Laos and Cambodia, again, both scored HAQ indices that are significantly below the ASEAN mean. According to the WHO, although there seems to be strong government commitment in Laos to improve healthcare services, as reflected by the number of healthcare policies that have been implemented, government health expenditure is still inadequate to give rise to significant transformations in healthcare [56]. As for Cambodia, its ministry of health aims to move toward universal healthcare coverage. However, without significant reduction in patient out-of-pocket (OOP) costs, universal healthcare remains to be far from reach [57].
With the sustained growth in population, major challenges in the provision of healthcare grow alongside it. Provision of care that is more accessible, and is at the same time, of good quality, in the Philippines is hindered by various obstacles such as limited clinic hours, clinician shortage (especially in remote areas), and poor transportation modes and infrastructure. As reported by the American Health Association, about 3.6 million people in the United States, although a developed country, are unable to acquire healthcare each year due to the lack of access to transportation [58]. Conventionally, acquiring healthcare entails travel, and distance proves to be a significantly detrimental barrier to healthcare for people in many places. Patients who live far from clinics and medical centers opt to "wait and see" whether their symptoms progress before visiting a physician. The Philippines, being an archipelago, many of whose islands do not possess the necessary infrastructure for travel to and from major cities, is especially vulnerable to this barrier. One potentially robust solution to this conundrum is the utilization of telecommunication channels. By architecting efficient channels between patient and healthcare providers, and networks among providers, we would be able to afford the ability to deliver care straight to the patient.

Amid the COVID-19 pandemic, the Department of Health (DOH) in the Philippines in collaboration with the National Privacy Commission (NPC), has developed a framework for telemedicine services to aid residents of the Philippines in accessing healthcare during the community lockdown [59]. The DOH utilizes technology in hopes of eliminating the problems brought about by the physical distance between patient and medical professional, thus allowing the public to receive healthcare without having to leave their homes [59]. The telemedicine service can be acquired over the phone, via chat, by short messaging service (SMS), or by video conferencing [59]. There is also an existing initiative by the private telecommunication service provider, Globe Telecom, which offers a health service hotline, called "konsultaMD." KonsultaMD provides access to licensed and professional physicians 24 hours a day, seven days a week. During this outbreak, the use of telemedicine could facilitate the mitigation of virus transmission in the country by enabling the provision of healthcare without the need for physical contact [60].

We cannot deny it. Technology is certainly making the world smaller. Today, technology helps make health services accessible wherever, whenever and whoever you are. As one would expect, customer experience plays a vital role in determining the approval that a product or service receives from the public [61]. The approval of a service provided by its clients increases the demand for the service. Moreover, digitalization has compelled man to prefer technology over manpower for various functions [61]. In a technologically driven world, many clients prefer digitally provided services 
that could allow for better customer experience. With technology, healthcare providers could offer patients convenience and save them the trouble of leaving their homes to seek medical care, even potentially on-demand whenever necessary. The objective of this technology is to change how Filipinos view and access healthcare. We live in a quickly developing world where disconnecting is difficult. We are moving into the age of wireless technology wherein all people could stay connected wherever and whenever with just a few clicks on the computer. Telemedicine would be cost-effective and time-efficient because patients could receive instant and constant medical advice directly from the physician. Telemedicine also provides physicians with a direct channel of communication whenever it is necessary, especially in cases of urgent and emergent need. With this technology, we would be able to redefine healthcare as a basic human right and need that can be satisfied outside the premises of clinics and hospitals where it is traditionally delivered.

Rather than assigning doctors to serve in remote areas to provide medical care over a fixed duration of time, it is significantly cheaper to provide the necessary medical equipment to perform tasks that do not necessarily require the presence of a physician by having the consultation take place through the use of information and communication technologies. In this manner, we save money and time. However, for this to be possible, it is imperative that we introduce training programs for physicians, allied health professionals, information technology (IT) personnel, and non-medical personnel [62]. Physicians and allied health professionals should be trained in the requisite information technology skills necessary to operate the telemedicine system, and IT personnel servicing the system need to be literate in basic knowledge of physiology and of the logistics necessary to manage this system. By making healthcare more accessible than ever, we could ensure a substantially healthy patient population in the future. Eventually, we would be able to shift the focus of healthcare delivery from curative to preventive [62].

\section{Singapore - an atypical Southeast Asian nation}

It is evident that Singapore consistently scores at least one standard deviation above the mean in all indicators presented in Table I, but scores at least one SD below the mean in all indicators presented in Table II, thus outperforming all of its neighboring nations. We could say that Singapore is far more advanced in terms of technology, quality of healthcare, accessibility of healthcare and standard of living, to the point of atypicality.

\section{E. Biomedical engineering solutions to preventable maternal mortalities}

In Table II, different causes of mortality were used to determine the performance of the healthcare systems in
ASEAN countries. Laos, Cambodia, and Myanmar have maternal mortality rates that are greater than the regional mean by more than one standard deviation. This would imply that mothers are at significantly greater risk of dying during or after childbirth in these countries. In most developing countries, the dearth of good-quality healthcare, proper family planning, access to trained labor, and emergency care contribute to the risk of maternal death. To address this problem, there are interventions focused toward abating maternal mortality and improving the conditions of mothers in the intrapartum and postpartum periods [63]. The Partnership for Global Health Technologies, for instance, connects students from Boston University and universities abroad to create affordable and innovative healthcare solutions for pressing health challenges. In addition to this, several smart devices such as those that continuously monitor blood pressure and automatically detect preeclampsia, which is a potentially fatal complication during pregnancy indicated by high blood pressure, have also been designed in order to evaluate a mother's condition [64].

\section{F. Biomedical engineering solutions to preventable neonatal mortalities}

In the year 2018, the WHO reported that despite the progress seen over the past two decades, 2.5 million newborns and 1.5 million infants aged one to 11 months died, mostly from preventable causes [65]. In Table II, it can be seen that of the 10 nations in the ASEAN, only five have neonatal mortality rates that are less than 10 for every 1000 live births Singapore, Brunei, Malaysia, Indonesia, and Thailand. The Philippines, Myanmar, and Cambodia have neonatal mortality levels above the mean, with Laos showing very poor control of its cases of neonatal death, i.e. a neonatal mortality rate that is greater than one standard deviation above the mean. Globally, the average annual rate of reduction in neonatal mortality from 1990 to 2019 was 2.5 percent, while that of children aged one to 59 months was 3.6 percent [66]. Cases of neonatal mortality are highest in low-income nations like those in sub-Saharan Africa and South Asia. It is said that a newborn in sub-Saharan Africa is 10 times more likely to die in the first month compared to a child born in developed countries such as Norway, Switzerland, and the United States, while a child born in South Asia is nine times more likely to die [66].

About 28 percent of neonatal deaths are caused by prematurity [67]. Every year, 24 million newborns develop jaundice [68], which is a common condition among premature infants. This occurs as a result of high levels of bilirubin present in these infants' blood, resulting in a yellowish discoloration of newborns' skin. If infants who have jaundice are left untreated, cognitive impairments, or worse, the death of these infants, may result [68]. With objectives to improve the conditions and survival rates of newborns, there are affordable and effective technologies that could prevent most neonatal and child deaths [69] - [72]. For instance, researchers in India 
conducted a study to measure the accuracy of "Biliscan," a software application that uses feature extraction and machine learning-based linear regression models to predict and to assess cases of jaundice in neonates. The data acquired from Biliscan were compared with measures of total serum bilirubin (TSB), which is the current gold standard, as reference. It was then found that there exists a good correlation of $\sim 0.6$ between Biliscan estimates and TSB levels [73]. Additionally, Pelham et al. designed a portable, accurate, and low-cost device called BiliSpec that is capable of quantifying TSB levels from small drops of whole blood applied to a lateral flow card. The sample is then inserted into a reader, which consists of three light emitting diodes (LEDs) with center peak wavelengths of 470 $\mathrm{nm}$ (blue), $590 \mathrm{~nm}$ (amber), and $660 \mathrm{~nm}$ (red), to measure light transmitted through the plasma on the card. The obtained measurement for transmitted light is then converted into a concentration of bilirubin. In high-income nations, mortality from infant jaundice is rare because of existing facilities and tools to treat newborns [72]. Jaundice can easily be treated by exposing the infant to blue light in order to reduce the concentration of bilirubin in his/her body [72], [74]. However, in low-income nations, there exists a dearth of essential medical technologies that renders diagnosing an otherwise diagnosable disease impossible [75], [76].

\section{G. Biomedical engineering solutions to curb deaths due to NCDs}

Annually, about 70 percent of global deaths can be attributed to noncommunicable diseases (NCDs). In addition, WHO estimates show that NCDs were responsible for the $15 \%$ rise in deaths between 2010 and 2020 [77, 78]. The South East Asian Region (SEAR) is estimated to account for the largest total number of deaths due to NCDs (10.4 million deaths in 2020) [77], [78]. With the alarming rise of threats brought about by NCDs to public health and to the economy, preventive policies and control programs against NCDs in the SEAR have been formed [79] - [82]. Among the 10 ASEAN nations, The Philippines, Laos and Myanmar report the highest risk of dying from NCDs with probabilities that are greater than one standard deviation above the ASEAN mean (Table II). NCDs in the Philippines account for 68 percent of the overall deaths. This, in turn, causes an increase in healthcare costs and a reduction in productivity in the country [83]. Similarly, a significant increase in NCD mortality from 46.9 percent in the year 2000 to 68 percent in 2017 was observed in Myanmar [84]. Studies conducted in Laos also show that NCDs, such as diabetes and cardiovascular diseases, are the main cause of death in the country [82]. Moreover, Cambodia reports a 21 percent probability of dying from NCDs that exceeds the mean by three percent (Table II). However, robust NCD intervention could avert 184,236 deaths and could potentially add 15 years to the average life expectancy of the infirm population [85]. Although the probabilities of mortality due to NCDs in countries such as Brunei, Vietnam, Indonesia, Thailand, and Malaysia are below the ASEAN mean, mortality is still high. Of all ASEAN member states, only Singapore reports a probability of NCDled mortality that is significantly below the ASEAN mean (Table II). Stroke, an NCD, is considered to be the most common cause of mortality and disability worldwide [86], [87]. Moreover, there were reports of 13.7 million new cases and 80.1 million prevailing cases of stroke globally in 2016 [86]. Among Southeast Asian nations, Laos and Indonesia have the greatest number of deaths due to stroke, while Singapore and Malaysia have less than 1000 cases of deaths caused by stroke (Table II). Stroke is common in Laos, accounting for 50 percent of all cardiovascular mortalities [88]. It is also considered to be the leading cause of death in Indonesia [89]. Often, stroke survivors suffer from temporary disabilities or even states of long-term paralysis, loss of speech, or coma. To alleviate the conditions of stroke survivors, rehabilitation therapies are essential. This is why attempts to integrate smart assistive solutions to ameliorate the condition of the disabled emerge alongside rapid technological developments. With the aim to enhance the physical functions of patients with disabilities, the integration of haptic interfaces, which are human-computer interaction systems that work through bodily sensation and action, may be utilized as assistive technologies for rehabilitation [90] - [93]. In the Philippines, the integration of assistive technologies in rehabilitation centers could better support the treatment provided to disabled patients. The benefits that accompany the inclusion of biomedical engineering in nationwide rehabilitation efforts for PWDs form a strong argument that biomedical engineering can, for certain, improve the quality of life of millions in the Philippines. Biomedical engineering research that focuses on affordable assistive technology, such as the Rehab Community-based Affordable Robot Exercise System (Rehab C.A.R.E.S), aims to improve the provision of therapy to persons with severe disabilities that arise from stroke in low- and middle-income countries [94]. The integration of these technologies across rehabilitation centers in the Philippines could benefit the $\sim 12$ percent of Filipinos [95], who suffer from severe disability.

Diabetes mellitus, another NCD, is responsible for the suffering of 475 million people worldwide. The figure is expected to grow to 642 million by 2040 [96]. Of the 10 ASEAN countries, the Philippines and Myanmar have the highest rates of deaths due to diabetes mellitus. The incidence of deaths due to diabetes mellitus in these countries are significantly above the ASEAN mean, while that of Singapore is significantly below (Table II). In the Philippines, diabetes mellitus is one of the four most common NCDs. Moreover, interventions for diabetes mellitus and cardiovascular diseases in the Philippines are the largest healthcare expenses, amounting to $\sim$ USD 1.4 billion over five years [97]. Myanmar, on the other hand, reports a higher number of cases of diabetes mellitus than all other ASEAN countries [98]. This is extended by information found in Table II, wherein it can be seen that 
the number of deaths caused by diabetes mellitus in Myanmar is significantly greater than the regional norm. To mitigate the burden and to ameliorate the life of diabetic patients, Alfian et al. created a personalized healthcare monitoring system that would allow diabetic patients to better manage their chronic disease. The proposed design utilizes Bluetooth low energy (BLE)-based sensors to monitor and gather vital signs, such as blood pressure, heart rate, weight, and blood glucose. Moreover, real-time data processing and machine learningbased algorithms were utilized to manage the large amount of data acquisition necessary [99]. With the large number of individuals who suffer from diabetes mellitus, there also exists a fair number of novel devices for insulin delivery in the market such as insulin pens and patch pumps. For instance, improved smart insulin delivery patches that monitor a patient's blood glucose and automatically inject insulin into the body whenever necessary are the subject of ongoing research and development [100]. Moreover, the field of biomedical engineering has paved the way for the creation of low-cost solutions, such as cost-effective insulin pumps for type-1 diabetic patients [101], and wearable devices, like V-GO ${ }^{\circledR}$, that use less expensive insulin (e.g. regular insulin) for type-2 diabetic patients [102]. These technologies could provide safe and effective treatments for patients with diabetes mellitus in low- and middle-income settings. In the Philippines alone, $\sim 6.3 \%$ of the adult population is afflicted with diabetes mellitus. Moreover, diabetic patients are exposed to long-term risk of complications that could be potentially life-threatening. Biomedical engineering-led research in low-cost diabetic technologies could give rise to the normalization and proliferation of devices that will help deter diabetes-associated complications and mitigate the risk of mortality due to diabetes.

Another NCD whose prognosis we use to evaluate healthcare quality in the ASEAN, is leukemia. In ASEAN countries, deaths due to leukemia are significantly below the regional mean in Vietnam and Singapore, while the remaining eight nations report deaths of five or greater for every 100,000 people due to leukemia (Table II). As a result of the rise of the ageing population and the transition to Western lifestyles, cases of cancer in ASEAN countries will continue to increase [103]. Today, there exists a wide array of treatments for patients with cancer, including surgery, radiation therapy, chemotherapy, and immunotherapy. Depending on the type of cancer, a patient may also undergo a combination of treatments. In addition, early detection of cancer could significantly increase the patients' likelihood of survival, as this will allow for provision of treatment before the disease progresses to more advanced stages [104]. With the rapid increase of technological influence in today's generation, diagnosis of disease and interpretation of medical data have greatly improved. Compared to past decades, physicians today have better access to medical imaging that provide rapid diagnostics to their patients any time of the day, any day of the week.

Medical Imaging is a set of diagnostic modalities [e.g. magnetic resonance imaging (MRI), ultrasound, medical radiation, projection radiography and computed tomography (CT)] that provide visual representations of anatomical structure and pathologies used in order to inform medical intervention. Another approach in treating cancer, called theranostics, makes use of one radioactive drug to identify the existence of cancer and a second radioactive agent to provide therapy. Theranostics, which is an amalgamation of the words diagnostics and therapeutics, aims to provide patients with exactly these. With theranostics, we can transition from providing "one-size-fits-all" solutions to providing a more personalized delivery of medicine [105]. Also, there are other approaches that offer cost-effective solutions, such as the utilization of microfluidic technology in understanding the behavior of cancer cell migration mechanisms [106]. Microfluidics is the science of fluid mechanics and the manipulation of fluids in the microscale. It enables highthroughput biological experiments that are cost-effective [107], by modeling the behavior and environment of macroscopic systems [108], [109]. Understanding how diseases, such as cancer, behave through extensive and repeated modeling in these microscale environments, as enabled by microfluidic technology, could lead to the discovery of novel drug delivery methods with much greater efficacy.

\section{H. Cost-effective solutions for congenital birth defects}

The incidence of deaths caused by congenital birth defects is significantly above the ASEAN mean in Laos and Myanmar. These are also the countries that have maternal mortality rates significantly above the ASEAN mean (Table II). In most developing countries, about four million children are born with birth defects. Moreover, 11 percent of global neonatal mortality can be attributed to these defects [110]. In the United States, the most common type of birth defect is the congenital heart defect (CHD), affecting about $1 \%$ of newborns per year [111]. However, over the past decades, advancements in healthcare have reduced the rate of mortality due to CHDs [112]. To address the issue that affects the quality of life of individuals born with CHDs, advances in technology and research have paved the way for innovative solutions, such as left ventricular assist devices (LVAD), which aid the pumping of the heart [113].

Tissue engineering is a sub-discipline of biomedical engineering that deals with the artificial fabrication of human tissue through the design of tissue scaffolds that accommodate cellular differentiation and proliferation [114]. Moreover, with the rapid progress in research, tissue engineering approaches show great potential for treating CHD [115]. For instance, tissue engineered bovine tissue pericardium scaffolds have 
been found to be cost-effective and durable, making them great for use in surgeries to treat CHD. CHD is considered to be one of the 10 leading causes of pediatric morbidity and mortality in the Philippines, affecting five to 10 newborns for every 1,000 in the country [116]. However, through the incorporation of tissue engineering approaches to the provision of healthcare, mortalities caused by CHDs could be averted and life expectancy could improve.

\section{PCCs between BME publication volume and indicators of healthcare quality}

In Table III, it can be seen that the PCCs between BME publication volume and each of the 12 indicators, and the PCCs between BME publication volume and the natural logarithm of the same indicators are dramatically higher when data from Brunei were excluded. Moreover, a similar phenomenon was observed in Figure 1, where the datapoints of Brunei exhibited anomalous behavior that did not seem to conform with the trends established through the data collected from the other nine ASEAN member states.

As previously mentioned in the METHODS section, a PCC of $\geq 0.8000$ indicates a strong correlation. Of the 12 Indicators, six showed optimal PCCs with magnitudes $\geq 0.9000-$ HDI value $(+0.9279)$, HAQ index $(+0.9072)$, GDP per capita $(+0.9599)$, NMR $(-0.9318)$, incidence of deaths due to diabetes mellitus (-0.9234), and incidence of deaths due to congenital birth defects (-0.9390). This suggests that the enumerated indicators share very strong relationships with BME publication volume. Furthermore, this implies that an increase in BME publication volume corresponds to an increase in HDI, HAQ Index, and GDP per capita, but to a decrease in NMR, incidence of deaths due to diabetes mellitus, and incidence of deaths due to congenital birth defects.

Moreover, five indicators have optimal PCCs with magnitudes $\geq 0.8000$ (but $<0.9000)$ - life expectancy at birth $(+0.8598)$, healthy life expectancy at birth $(+0.8800)$, maternal mortality ratio (-0.8822), probability of dying from NCDs (-0.8430), and stroke $(-0.8510)$. This is an indication that there exist strong relationships between BME publication volume and these five indicators. It could also be said that an increase in BME publication volume corresponds to a rise in life expectancy at birth and healthy life expectancy at birth, but to declines in maternal mortality ratio, probability of dying from NCDs, and stroke. Finally, the incidence of deaths due to leukemia was found to have an optimal PCC of -0.7069 with BME publication volume. Despite it being an accepted measurement $(>0.6000)$, it has the weakest relationship among the 12 healthcare indicators.

\section{J. Biomedical engineering research as a driver for heightened healthcare quality}

Of the 12 indicators plotted against the number of $\mathrm{BME}$ publications, logarithmic fits were obtained for three (GDP per capita, maternal mortality ratio, and congenital birth defects). Figure 1(a) presents a logarithmic relationship between BME publication yield and GDP per capita with $\mathrm{R}^{2}=0.5161$ and $\mathrm{R}^{2 *}$ $=0.9214$. A logarithmic function comprises an initial phase characterized by a transient increase succeeded by a saturation. As observed in the graph, ASEAN countries that have higher GDP per capita values tend to yield more biomedical engineering research publications compared with those with lower GDP per capita values. This is probably attributable to the fact that countries with higher GDP per capita values possess more funds to allocate toward the development of biomedical engineering research. However, looking at the behavior of the graphs, it can be observed that as GDP per capita increases, the number of BME publications increases but at a declining rate. This could mean that despite increases in funding allocated toward biomedical engineering research, publication yield eventually saturates. This appears to be consistent with Eroom's law, which states that the developments in biomedicine decelerate and become costlier with time. However, this does not mean that researchers in the field of biomedicine are becoming less competent over time. Rather, it means that biomedical research becomes more complex with time. It could also mean that as GDP per capita increases, a smaller fraction is allocated toward $\mathrm{BME}$ research.

Figure 1(f) presents the graph of MMR plotted against BME publication yield with $\mathrm{R}^{2}=0.7457$ and $\mathrm{R}^{2^{*}}=0.9433$, which was the best coefficient of determination in this study. In this figure, the graph decays rapidly, i.e. as BME publication yield increases, the incidence of maternal deaths decreases dramatically until eventually, it reaches a point where a country breaks the threshold of about 1000 publications. Upon reaching this threshold, the curve begins to approach what appears to be an asymptote. A similar phenomenon is observed in Figure $1(\mathrm{k})\left(\mathrm{R}^{2}=0.8095\right.$ and slightly smaller $\mathrm{R}^{2^{*}}$ $=0.8960$ ) where the rate of decline slows down and approaches an asymptote.

In addition, four of the 12 indicators - neonatal mortality rate [Figure 1(g)], probability of dying from NCDs [Figure 1(h)], incidence of deaths due to stroke [Figure 1(i)], and incidence of deaths due to diabetes mellitus [Figure 1(j)], decay exponentially when plotted against BME publication yield.

A key observation in Figure $1(\mathrm{~g})\left(\mathrm{R}^{2}=0.7517\right.$ and $\mathrm{R}^{2^{*}}=$ 0.8682 ) was that there was a sudden decline in neonatal deaths, which was not captured by the exponential fit, as BME publication yield increased from four to seven. Here, Laos, which yielded four BME publications, reported 23 neonatal deaths, while Cambodia, which yielded seven BME publications, reported only 14 neonatal deaths. By examining the numbers, it can be seen that an increment of only three publications was associated with a drastic decrease of $39.13 \%$ in neonatal deaths. It is essential to point out that we are not 
establishing causation here. Rather, one of many ways to interpret this is to see that countries that have low yields of biomedical engineering research might give less importance to the improvement of healthcare systems and the quality of healthcare. Another reason might be that they lack the resources to allocate toward the two-faceted objective (biomedical technology and healthcare policy) of improving healthcare, even if it were an objective of prime importance. As a result, many people die from preventable causes.

In Figure 1(b), it can be observed that as BME publication yield grows, a corresponding increase in HDI can be associated with it $\left(\mathrm{R}^{2}=0.5708\right.$ and $\left.\mathrm{R}^{2^{*}}=0.8612\right)$. In a similar manner, Figure 1(c), 1(d), and 1(e) exhibit the same phenomenon but with less favorable $\mathrm{R}^{2 *}$ scores of 0.8230 , 0.7393 , and 0.7745 , respectively $\left(R^{2}\right.$ scores of $0.5473,0.5720$, and 0.6207 , respectively). Lastly, Figure 1(1) shows no apparent trend having the lowest scores for both $\mathrm{R}^{2}=0.3667$ and $\mathrm{R}^{2^{*}}=0.4771$ among the 12 indicators of healthcare quality.

\section{CONCLUSION}

Although causation cannot be established in this study, indeed, substantial and measurable relationships were found between biomedical engineering research and each of the 12 indicators of healthcare quality. Hence, we feel that it is safe to postulate that by gearing healthcare development efforts toward innovative engineering solutions, many of which have been made cost-effective and affordable, the Philippines, like many of its ASEAN neighbors, would be able to drive healthcare access and quality forward for its citizens. For this reason, we believe that it is certainly time for the Philippines to adopt $\mathrm{BME}$ as an academic and professional discipline in its own right, so that it may one day enjoy the benefits brought about by advancements in the provision of healthcare that are experienced by its ASEAN neighbors that have already gone ahead with movements to cultivate the highly essential discipline.

We hope that this article inspires leaders in academe, industry, and policy to take their first steps in realizing this endeavor. Leaders in academe could form a consortium among universities across the Philippines that would push for initiatives to establish BME as an academic and professional discipline and that would allow members to benefit from the expertise of specialists from partner institutions. Partnerships could be initiated between academic institutions and firms that develop biomedical technologies, so that firms could provide the requisite industry training to budding biomedical engineers, and in turn, would benefit from the human resource fostered by academic institutions. From the perspective of policy, the Department of Science and Technology is the most appropriate agency of government to define BME as an academic discipline by channeling funding toward the training of experts in BME and toward innovative research that will drive the discipline forward. It will take only a few first movers to build the momentum that later propagators would be able to ride.

\section{ACKNOWLEDGMENT}

We would like to thank Mr. Vinosh J. Mathuranayagam and Ms. Olivia Licata for highly useful discussions and feedback.

\section{REFERENCES}

[1] F. R. Lichtenberg, "The impact of biomedical innovation on longevity and health", Nordic Journal of Health Economics, vol. 5, no. 1, pp. 45-57, 2015, doi: 10.5617/njhe. 1290.

[2] V. R. Fuchs, "New priorities for future biomedical innovations," The New England Journal of Medicine, vol. 363, no. 8, pp. 704 706, Aug. 2010, doi: 10.1056/NEJMp0906597.

[3] D. M. Cutler, A. S. Deaton, and A. Lleras-Muney, "The Determinants of Mortality," National Bureau of Economic Research, Working Paper 11963, Jan. 2006. doi: 10.3386/w11963

[4] E. Kramarow, J. Lubitz, H. Lentzner, and Y. Gorina, "Trends in the health of older Americans, 1970-2005," Health Affairs (Project Hope), vol. 26, no. 5, pp. 1417-1425, Oct. 2007, doi: 10.1377/hlthaff.26.5.1417.

[5] M. R. Al Asif, S. Roy, A. Abdullah, M. Raihan, R. Akter and M. Z. Hossain, "Role and Impact of Biomedical Engineering Discipline for Developing Country Perspective", International Journal of Innovative Research in Computer Science \& Technology, vol. 6, no. 4, pp. 87-90, 2018, doi: 10.21276/ijircst.2018.6.4.9.

[6] World Health Organization, "Human Resources for Medical Devices: The role of biomedical engineers", World Health Organization, Geneva, 2017.

[7] F. Nebeker, "Golden accomplishments in biomedical engineering," in IEEE Engineering in Medicine and Biology Magazine, vol. 21, no. 3, pp. 17-47, May-June 2002, doi: 10.1109/MEMB.2002.1016851.

[8] J. D. Bronzino, "Biomedical Engineering: A Historical Perspective", in Introduction to Biomedical Engineering, 2nd ed., J. D. Enderle, J. D. Bronzino and S. M. Blanchard, Ed. Oxford: Academic Press, 2005, pp. 1-29.

[9] World Health Organization, "Global strategy on human resources for health: Workforce 2030", World Health Organization, Geneva, 2020.

[10] World Health Organization, "Human Resources for Medical Devices: The role of biomedical engineers", World Health Organization, Geneva, 2017.

[11] International Labour Office, "International Standard Classification of Occupations: Structure, group definitions and correspondence tables", International Labour Organization, Geneva, 2012.

[12] J. Webster, "Biomedical Engineering in Malaysia," in IEEE Engineering in Medicine and Biology Magazine, vol. 23, no. 6, pp. 12-13, Nov.-Dec. 2004, doi: 10.1109/MEMB.2004.1378625.

[13] N. A. Kadri, M. G. Raha, N. A. Abu Osman and W. A. B. Wan Abas, "The First Decade of Biomedical Engineering Degree Program at the University of Malaya: Experiences and Achievements", in 4th Kuala Lumpur International Conference on Biomedical Engineering 2008, Kuala Lumpur, 2008, pp. 6972.

[14] "Department of Biomedical Engineering: History \& Milestones", National University of Singapore (NUS) Engineering, 2020. [Online]. Available: https:/www.eng.nus.edu.sg/bme/about-us/history-milestones/. [Accessed: 02- Oct- 2020].

[15] "Why Biomedical Engineering", Bandung Institute of Technology - School of Electrical Engineering and Informatics Biomedical Engineering. [Online]. Available: 
https://biomed.stei.itb.ac.id/en/why-biomedical-engineering/. [Accessed: 02- Oct- 2020].

[16] "Biomedical Engineering Society in Vietnam", Biomedical Engineering Society in Vietnam, 2020. [Online]. Available: http://bmevn.org/. [Accessed: 02- Oct- 2020].

[17] "The Czech Republic will support the development of biomedical engineering in Cambodia", Embassy of the Czech Republic in Phnom Penh, 2020. [Online]. Available: https://www.mzv.cz/phnompenh/en/development_cooperation and business/the czech republic will support the.html. [Accessed: 02- Oct- 2020].

[18] N. Bugtai, "Program Title: Establishment of the Institute of Biomedical Engineering and Health Technologies (IBEHT)", Philippine International Convention Center, Pasay City, Philippines, 2020.

[19] F. Frost, "ASEAN's regional cooperation and multilateral relations: recent developments and Australia's interests", Parliament of Australia, 2008.

[20] "GDP per capita (current US\$) | Data", The World Bank, 2020 [Online]. https://data.worldbank.org/indicator/NY.GDP.PCAP.CD [Accessed: 02- Oct- 2020].

[21] World Health Organization, "World Health Statistics 2020: Monitoring health for the SDGs", Geneva, 2020.

[22] "SJR - International Science Ranking", Scimagojr.com, 2020 [Online]. Available: https://www.scimagojr.com/countryrank.php. [Accessed: 08Oct- 2020].

[23] "Country Profiles", Institute for Health Metrics and Evaluation, 2020. [Online]. Available: http://www.healthdata.org/results/country-profiles. [Accessed: 02- Oct- 2020].

[24] "2019 Human Development Index Ranking | Human Development Reports", United Nations Development Programme, 2020. [Online]. Available: http:/hdr.undp.org/en/content/2019-human-developmentindex-ranking. [Accessed: 02- Oct- 2020]

[25] "Global Burden of Disease Visualisations: Cause of Death", The Lancet, 2020.2 [Online]. Available: https://www.thelancet.com/lancet/visualisations/cause-of-death. [Accessed: 02- Oct- 2020].

[26] M. Falagas, V. Kouranos, R. Arencibia-Jorge and D. Karageorgopoulos, "Comparison of SCImago journal rank indicator with journal impact factor", The FASEB JOURNAL, vol. 22 , no. 8 , pp. 2623-2628, 2008. [Accessed 12 October 2020].

[27] "Human Development Index (HDI) | Human Development Reports", United Nations Development Programme. [Online]. Available: http://hdr.undp.org/en/content/human-developmentindex-hdi. [Accessed: 02- Oct- 2020].

[28] M. C. Stiefel, R. J. Perla, and B. L. Zell, "A healthy bottom line: healthy life expectancy as an outcome measure for health improvement efforts," Milbank Q, vol. 88, no. 1, pp. 30-53, Mar. 2010, doi: 10.1111/j.1468-0009.2010.00588.x.

[29] WHO, UNICEF, UNFPA, and The World Bank, "Trends in Maternal Mortality: 1990 to 2008 - Estimates developed by WHO, UNICEF, UNFPA and The World Bank", World Health Organization Press, Geneva, 2010

[30] K. Elmusharaf, E. Byrne, and D. O'Donovan, "Strategies to increase demand for maternal health services in resource-limited settings: challenges to be addressed," BMC Public Health, vol. 15, pp. 870-870, Sep. 2015, doi: 10.1186/s12889-015-2222-3.

[31] J. W. Vaupel, "Biodemography of human ageing", Nature, vol. 464, no. 7288, pp. 536-542, 2010, doi: 10.1038/nature08984.

[32] World Health Organization, "Towards Policy for Health and Ageing", 2003.

[33] E. Fuentes, M. Fuentes, M. Alarcon, and I. Palomo, "Immune System Dysfunction in the Elderly", Anais da Academia Brasileira de Ciências, vol. 89, no. 1, pp. 285-299, 2017, doi: 10.1590/0001-3765201720160487.
[34] J. M. van Deursen, "The role of senescent cells in ageing", Nature, vol. 509, no. 7501, pp. 439-446, 2014, doi: 10.1038/nature13193.

[35] B. G. Childs, D. J. Baker, J. L. Kirkland, J. Campisi and J. M. Deursen, "Senescence and apoptosis: dueling or complementary cell fates?", EMBO reports, vol. 15, no. 11, pp. 1139-1153, 2014, doi: $10.15252 / \mathrm{embr} .201439245$.

[36] G. Pizzino et al., "Oxidative Stress: Harms and Benefits for Human Health", Oxidative Medicine and Cellular Longevity, vol. 2017 , p. 8416763 , July 2017 , doi: $10.1155 / 2017 / 8416763$.

[37] R. Rau, E. Soroko, D. Jasilionis and J.W. Vaupel, "Continued Reductions in Mortality at Advanced Ages", Population and Development Review, vol. 34, no. 4, pp. 747-768, 2008, doi: 10.1111/j.1728-4457.2008.00249.x.

[38] K. M. Murphy and R. H. Topel, "The Value of Health and Longevity", Journal of Political Economy, vol. 114, no. 5, pp. 871-904, 2006, doi: 10.1086/508033.

[39] J. -M. Robine, Y. Saito and C. Jagger, "The relationship between longevity and healthy life expectancy", Quality in Ageing and Older Adults, vol. 10, no. 2, pp. 5-14, 2009, doi: 10.1108/14717794200900012.

[40] National Research Council (US) Panel on a Research Agenda and New Data for an Aging World, "Preparing for an Aging World: The Case for Cross-National Research", Population (French Edition), vol. 56, no. 5, p. 885, 2001. doi: $10.2307 / 1534892$.

[41] E. C. Norton, "Chapter 16 - Health and Long-Term Care," in Handbook of the Economics of Population Aging, vol. 1, J. Piggott and A. Woodland, Eds. North-Holland, 2016, pp. 951989.

[42] A. Nagl, J. Witte, J. M. Hodek, and W. Greiner, Relationship between multimorbidity and direct healthcare costs in an advanced elderly population. Results of the PRISCUS trial," Zeitschrift Fur Gerontologie Und Geriatrie, vol. 45, no. 2, pp. 146-154, Feb. 2012, doi: 10.1007/s00391-011-0266-2.

[43] [43] E. Park, J. Kwon, E. Lee, Y. Jung and S. Park, "Out-ofpocket Medication Expenditure Burden of Elderly Koreans with Chronic Conditions", International Journal of Gerontology, vol. 9, no. 3, pp. 166-171, 2015. Available: 10.1016/j.ijge.2014.06.005.

[44] "The Economic Impact of Long-Term Care on Individuals," ASPE, Dec. 09, 2015. https://aspe.hhs.gov/basicreport/economic-impact-long-term-care-individuals (accessed Oct. 02, 2020)

[45] C. J. Fahey, “The Long-Term Care Burden," Health Affairs, vol. 21, no. 1, pp. 274-274, Jan. 2002, doi: 10.1377/hlthaff.21.1.274

[46] R. V. Smith and J. H. L. Jr, Rehabilitation Engineering. CRC Press, 1990, pp. 1-2

[47] "Rehabilitation Engineering \& Rehabilitation Technology." https://resna.stanford.edu/RE\&T-PSG/ncmmr.htm (accessed Oct. 02, 2020).

[48] E. VanBergeijk, "Rehabilitation Engineer," in Encyclopedia of Autism Spectrum Disorders, F. R. Volkmar, Ed. New York, NY: Springer, 2013, pp. 2540-2540.

[49] S. Wilcher, "The Rehabilitation Act of 1973: 45 Years of Activism and Progress." https://www.insightintodiversity.com/the-rehabilitation-act-of1973-45-years-of-activism-and-progress/ (accessed Oct. 02, 2020).

[50] Rehabilitation Act of 1973, vol. 1-753. Washington, D.C.: United States Government Publishing Office, 1973.

[51] Department of Education, "Fiscal Year 2019 Budget", 2020.

[52] "Asia's First Assistive Technology, Integrated Care \& Rehab Engineering Event Launched in Singapore - News Archives ICCA Member Press Releases ICCA." https://www.iccaworld.org/newsarchives/archivedetails.cfm?id $=2793($ accessed Oct. 02, 2020).

[53] Y. Bouteraa, I. B. Abdallah, and A. M. Elmogy, "Training of Hand Rehabilitation Using Low Cost Exoskeleton and VisionBased Game Interface,” J Intell Robot Syst, vol. 96, no. 1, pp. 31-47, Oct. 2019, doi: 10.1007/s10846-018-0966-6. 
[54] G. Carpino, A. Pezzola, M. Urbano, and E. Guglielmelli, "Assessing Effectiveness and Costs in Robot-Mediated Lower Limbs Rehabilitation: A Meta-Analysis and State of the Art," Journal of Healthcare Engineering, vol. 2018, p. 7492024, Jun. 2018, doi: 10.1155/2018/7492024

[55] D. Karia, R. S. Nambiar, and M. Arora, "An Affordable Insulin Pump for Type-1 Diabetic Patients: A Case Study of User-inthe-Loop Approach to Engineering Design," Proceedings of the Design Society: International Conference on Engineering Design, vol. 1, no. 1, pp. 847-856, 2019, doi: 10.1017/dsi.2019.89.

[56] K. Akkhavong et al., " The Lao People's Democratic Republic Health System Review", Health Systems in Transition, vol. 4, no. 1, 2014. [Accessed 2 October 2020].

[57] P. L. Annear et al., "The Kingdom of Cambodia Health System Review", Health Systems in Transition, vol. 5, no. 2, 2015. [Accessed 2 October 2020].

[58] "HPOE.org - Social Determinants of Health Series: Transportation." http://www.hpoe.org/resources/ahahretguides $/ 3078$ (accessed Oct. 08, 2020).

[59] "DOH Boosts Telemedicine Services for NCR; Services to Expand to Other Regions Soon | Department of Health website." https://www.doh.gov.ph/doh-press-release/DOH-BOOSTTELEMEDICINE-SERVICES-FOR-NCR-SERVICE-TOEXPAND-TO-OTHER-REGIONS-SOON (accessed Oct. 02, 2020).

[60] "Using Telehealth Services", Centers for Disease Control and Prevention, 2020. [Online]. Available: https://www.cdc.gov/coronavirus/2019 ncov/hcp/telehealth.html. [Accessed: 02- Oct- 2020].

[61] P. Foroudi, S. Gupta, U. Sivarajah, and A. Broderick, "Investigating the effects of smart technology on customer dynamics and customer experience," Computers in Human Behavior, vol. 80, pp. 271-282, Mar. 2018.

[62] R. L. Macabasag, K. M. Magtubo, and P. Marcelo, "Implementation of Telemedicine Services in Lower-Middle Income Countries: Lessons for the Philippines," Journal of the International Society for Telemedicine and eHealth, vol. 4, pp. 1-11, Dec. 2016.

[63] N. M. Nour, "An introduction to maternal mortality," Rev Obstet Gynecol, vol. 1, no. 2, pp. 77-81, 2008.

[64] I. Marin, N. Goga, A. Vasilateanu, A. Gradinaru and V. Racovita, "Smart Solution for the Detection of Preeclampsia," 2019 E-Health and Bioengineering Conference (EHB), Iasi, Romania, 2019, pp. 1-4, doi: 10.1109/EHB47216.2019.8969948.

[65] UNICEF, WHO, World Bank, UN-DESA Population Division, "Levels and trends in child mortality report 2019: Estimates developed by the UN Inter-agency Group for Child Mortality Estimation", 2020.

[66] "Neonatal mortality," UNICEF DATA https://data.unicef.org/topic/child-survival/neonatal-mortality/ (accessed Oct. 02, 2020).

[67] L. L. Wright, "Chapter 4 - Global Neonatal Health," in Avery's Diseases of the Newborn (Ninth Edition), Gleason Christine A and S. U. Devaskar, Eds. Philadelpia: W.B. Saunders, 2012, pp. 23-36.

[68] P. A. Keahey et al., "Point-of-care device to diagnose and monitor neonatal jaundice in low-resource settings," Proceedings of the National Academy of Sciences of the United States of America, vol. 114, no. 51, pp. E10965-E10971, 19 2017, doi: 10.1073/pnas.1714020114.

[69] "Strategies for Reducing Maternal Mortality: Getting on with What Works," Obstetric Anesthesia Digest, vol. 27, no. 2, p. 60 , Jun. 2007.

[70] G. L. Darmstadt et al., "Evidence-based, cost-effective interventions: how many newborn babies can we save?," Lancet (London, England), vol. 365, no. 9463, pp. 977-988, Mar. 2005, doi: 10.1016/S0140-6736(05)71088-6.

[71] K. J. Kerber, J. E. de Graft-Johnson, Z. A. Bhutta, P. Okong, A. Starrs, and J. E. Lawn, "Continuum of care for maternal, newborn, and child health: from slogan to service delivery,"
Lancet (London, England), vol. 370, no. 9595, pp. 1358-1369, Oct. 2007, doi: 10.1016/S0140-6736(07)61578-5.

[72] Z. A. Bhutta et al., "Alma-Ata: Rebirth and Revision 6 Interventions to address maternal, newborn, and child survival: what difference can integrated primary health care strategies make?," Lancet (London, England), vol. 372, no. 9642, pp. 972 989, Sep. 2008, doi: 10.1016/S0140-6736(08)61407-5.

[73] S. Swarna, S. Pasupathy, B. Chinnasami, N. M. D. and B. Ramraj, "The smart phone study: assessing the reliability and accuracy of neonatal jaundice measurement using smart phone application", International Journal of Contemporary Pediatrics, vol. 5, no. 2, p. 285, 2018, doi: 10.18203/23493291.ijcp20175928.

[74] I. Pinto, A. Bogi, F. Picciolo, N. Stacchini, G. Buonocore, and C. V. Bellieni, "Blue Light and Ultraviolet Radiation Exposure from Infant Phototherapy Equipment," Journal of Occupational and Environmental Hygiene, vol. 12, no. 9, pp. 603-610, 2015, doi: $10.1080 / 15459624.2015 .1029611$

[75] B. T. Doumas et al., "Candidate reference method for determination of total bilirubin in serum: development and validation.," Clin Chem, vol. 31, no. 11, pp. 1779-1789, Nov. 1985, doi: 10.1093/clinchem/31.11.1779.

[76] N. Blanckaert, P. M. Kabra, F. A. Farina, B. E. Stafford, L. J. Marton, and R. Schmid, "Measurement of bilirubin and its monoconjugates and diconjugates in human serum by alkaline methanolysis and high-performance liquid chromatography," The Journal of Laboratory and Clinical Medicine, vol. 96, no. 2, pp. 198-212, Aug. 1980

[77] M. Reddy and S. Kar, "Unconditional probability of dying and age-specific mortality rate because of major non-communicable diseases in India: Time trends from 2001 to 2013," J Postgrad Med, vol. 65, no. 1, pp. 11-17, 2019, doi: 10.4103/jpgm.JPGM 52917 .

[78] World Health Organization, "Global status report on noncommunicable diseases 2010", 2011.

[79] World Health Organization Regional Office for South East Asia, "Second South-East Asia regional forum to accelerate NCD prevention and control in the context of SDGs," Art. no. SEANCD-101, 2020, Accessed: Oct. 08, 2020. [Online]. Available: https://apps.who.int/iris/handle/10665/334274.

[80] M. Ezzati, J. Pearson-Stuttard, J.E. Bennett, and C. D. Mathers, "Acting on non-communicable diseases in low- and middleincome tropical countries," Nature, vol. 559, no. 7715, Art. no. 7715, Jul. 2018, doi: 10.1038/s41586-018-0306-9.

[81] J. Lim, M. M. H. Chan, F.Z. Alsagoff, and D. Ha, "Innovations in non-communicable diseases management in ASEAN: a case series," Global Health Action, vol. 7, p. 25110, 2014, doi 10.3402/gha.v7.25110.

[82] A. Dans, N. Ng, C. Varghese, E. S. Tai, R. Firestone, and R. Bonita, "The rise of chronic non-communicable diseases in southeast Asia: time for action," Lancet (London, England), vol 377, no. 9766, pp. 680-689, Feb. 2011, doi: 10.1016/S01406736(10)61506-1.

[83] World Health Organization and United Nations Development Programme, "Prevention and control of noncommunicable diseases in the Philippines The case for investment", World Health Organization, 2019.

[84] E. E. Swe, K. K. K. Htet, P. Thekkur, L. L. Aung, L. L. Aye, and T. Myint, "Increasing trends in admissions due to noncommunicable diseases over 2012 to 2017: findings from three large cities in Myanmar," Trop Med Health, vol. 48, Apr. 2020 , doi: 10.1186/s41182-020-00209-8

[85] A. Kulikov, A. Mehta, D. Tarlton, D. Grafton and R. Aarsand, "Prevention and control of noncommunicable diseases in Cambodia The case for investment", World Health Organization, Manila, 2019.

[86] GBD 2016 Stroke Collaborators, "Global, regional, and national burden of stroke, 1990-2016: a systematic analysis for the Global Burden of Disease Study 2016," The Lancet. Neurology, vol. 18, no. 5, pp. 439-458, 2019, doi: 10.1016/S1474-4422(19)30034- 
[87] M. Gowshall and S. D. Taylor-Robinson, "The increasing prevalence of non-communicable diseases in low-middle income countries: the view from Malawi," Int J Gen Med, vol. 11, pp. 255-264, Jun. 2018, doi: 10.2147/IJGM.S157987.

[88] Lao People's Democratic Republic, "Report on STEPS Survey on Non Communicable Diseases Risk Factors in Vientiane Capital city, Lao PDR", 2010.

[89] K. Peltzer and S. Pengpid, "The Prevalence and Social Determinants of Hypertension among Adults in Indonesia: A Cross-Sectional Population-Based National Survey," International Journal of Hypertension, vol. 2018, p. 5610725, Aug. 2018, doi: 10.1155/2018/5610725

[90] R. L. Williams II, M. Srivastava, R. R. Conatser Jr. and J. N. Howell, "Implementation and Evaluation of a Haptic Playback Sytem", Haptics-e, vol. 3, no. 3, pp. 1-6, 2004.

[91] G. Srimathveeravalli and K. Thenkurussi, "Motor skill training assistance using haptic attributes," First Joint Eurohaptics Conference and Symposium on Haptic Interfaces for Virtual Environment and Teleoperator Systems. World Haptics Conference, Pisa, Italy, 2005, pp. 452-457, doi: 10.1109/WHC.2005.96.

[92] C. L. Teo, E. Burdet and H. P. Lim, "A robotic teacher of Chinese handwriting," Proceedings 10th Symposium on Haptic Interfaces for Virtual Environment and Teleoperator Systems. HAPTICS 2002, Orlando, FL, USA, 2002, pp. 335-341, doi: 10.1109/HAPTIC.2002.998977.

[93] N. Jafari, K. Adams and M. Tavakoli, "Haptics to improve task performance in people with disabilities: A review of previous studies and a guide to future research with children with disabilities", Journal of Rehabilitation and Assistive Technologies Engineering, vol. 3, pp. 1-13, 2016, doi: $10.1177 / 2055668316668147$.

[94] M. J. Johnson, R. Rai, S. Barathi, R. Mendonca and K. Bustamante-Valles, "Affordable stroke therapy in high-, lowand middle-income countries: From Theradrive to Rehab CARES, a compact robot gym", Journal of Rehabilitation and Assistive Technologies Engineering, vol. 4, pp. 1-12, 2017, doi: 10.1177/2055668317708732.

[95] Philippine Statistics Authority, "Disability Spares No One: A New Perspective", 2019.

[96] "Smart Meter fights diabetes in real-time." https://www.vodafone.com/business/news-and-insights/casestudy/smart-meter-fights-diabetes-in-real-time (accessed Oct. 09, 2020).

[97] World Health Organization, United Nations Development Programme, "Prevention and control of noncommunicable diseases in the Philippines: The case for investment", 2019.

[98] T. -S. Latt et al., "Measurement of diabetes, prediabetes and their associated risk factors in Myanmar 2014," Diabetes Metab Syndr Obes, vol. 12, pp. 291-298, Mar. 2019, doi: 10.2147/DMSO.S156270.

[99] G. Alfian, M. Syafrudin, M. F. Ijaz, M. A. Syaekhoni, N. L. Fitriyani and J. Rhee, "A Personalized Healthcare Monitoring System for Diabetic Patients by Utilizing BLE-Based Sensors and Real-Time Data Processing", Sensors, vol. 18, no. 7, p. 2183, 2018. doi: 10.3390/s18072183.

[100] J. Yu et al., "Glucose-responsive insulin patch for the regulation of blood glucose in mice and minipigs," Nature Biomedical Engineering, vol. 4, no. 5, pp. 499-506, 2020, doi: 10.1038/s41551-019-0508-y.

[101] D. Karia, R. S. Nambiar, and M. Arora, "An Affordable Insulin Pump for Type-1 Diabetic Patients: A Case Study of User-inthe-Loop Approach to Engineering Design," Proceedings of the Design Society: International Conference on Engineering Design, vol. 1, no. 1, pp. 847-856, 2019, doi: 10.1017/dsi.2019.89.

[102] "Wearable device lets patients with type 2 diabetes safely use affordable insulin option," ScienceDaily. https://www.sciencedaily.com/releases/2020/03/200331093256 .htm (accessed Oct. 2, 2020).

[103] M. Woodward, "A consensus plan for action to improve access to cancer care in the association of Southeast Asian Nations
(ASEAN) region," Asian Pacific journal of cancer prevention: APJCP, vol. 15, no. 19, pp. 8521-8526, 2014, doi 10.7314/apjcp.2014.15.19.8521.

[104] O. L. Gobbo, K. Sjaastad, M. W. Radomski, Y. Volkov and A. Prina-Mello, "Magnetic Nanoparticles in Cancer Theranostics", Theranostics, vol. 5, no. 11, pp. 1249-1263, 2015, doi: 10.7150/thno.11544.

[105] S. Jeelani, R. C. J. Reddy, T. Maheswaran, G. S. Asokan, A. Dany, and B. Anand, "Theranostics: A treasured tailor for tomorrow," J Pharm Bioallied Sci, vol. 6, no. Suppl 1, pp. S6S8, Jul. 2014, doi: 10.4103/0975-7406.137249

[106] Y. Huang, B. Agrawal, D. Sun, J. S. Kuo, and J. C. Williams, "Microfluidics-based devices: New tools for studying cancer and cancer stem cell migration," Biomicrofluidics, vol. 5, no. 1, Mar. 2011, doi: 10.1063/1.3555195.

[107] S. P. Kojic, G. M. Stojanovic, and V. Radonic, "Novel CostEffective Microfluidic Chip Based on Hybrid Fabrication and Its Comprehensive Characterization," Sensors (Basel), vol. 19, no. 7, Apr. 2019, doi: 10.3390/s19071719.

[108] G. Velve-Casquillas, M. Le Berre, M. Piel, and P. T. Tran, "Microfluidic tools for cell biological research," Nano Today, vol. 5, no1. 1, pp. 28-47, Feb. 2010, doi 10.1016/j.nantod.2009.12.001.

[109] H.-T. Nguyen, H. Thach, E. Roy, K. Huynh, and C. M.-T. Perrault, "Low-Cost, Accessible Fabrication Methods for Microfluidics Research in Low-Resource Settings," Micromachines (Basel), vol. 9, no. 9, Sep. 2018, doi: 10.3390/mi9090461.

[110] Institute of Medicine, "Reducing Mortality and Morbidity from Birth Defects", in Improving Birth Outcomes: Meeting the Challenge in the Developing World, Washington, D.C.: The National Academies Press, 2003, pp. 236-261.

[111] CDC, "Estimates of People in the US with CHDs | CDC," Centers for Disease Control and Prevention, Nov. 13, 2019 https://www.cdc.gov/ncbddd/heartdefects/features/kf-chdestimates-us.html (accessed Oct. 02, 2020).

[112] S. M. Gilboa et al., "Congenital Heart Defects in the United States: Estimating the Magnitude of the Affected Population in 2010," Circulation, vol. 134, no. 2, pp. 101-109, Jul. 2016, doi: 10.1161/CIRCULATIONAHA.115.019307.

[113] C. Brouwers, J. Denollet, N. de Jonge, K. Caliskan, J. Kealy and S. S. Pedersen, "Patient-Reported Outcomes in Left Ventricular Assist Device Therapy", Circulation: Heart Failure, vol. 4, no. 6 , pp. 714-723, 2011, doi: 10.1161/circheartfailure.111.962472.

[114] B. Chan and K. Leong, "Scaffolding in tissue engineering: general approaches and tissue-specific considerations", Springer, vol. 17, no. 4, pp. 467-479, 2008, doi: 10.1007/s00586-008-0745-3.

[115] A. Mantakaki, A. O. J. Fakoya, and F. Sharifpanah, "Recent advances and challenges on application of tissue engineering for treatment of congenital heart disease," PeerJ, vol. 6, Oct. 2018, doi: 10.7717 peerj.5805.

[116] J. G. Reganion, "Transcatheter Intervention of Congenital Heart Diseases: 40-Years Philippine Heart Center experience", Philippine Heart Center Journal, vol. 20, no. 1, pp. $1-9,2015$.

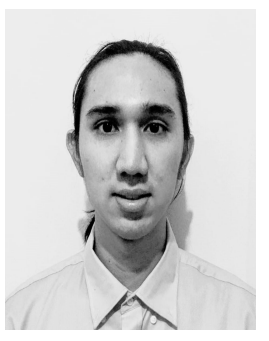

Jamie L. Fermin (StM'20) was born in Bacolod City, Philippines in 1999. He is currently an undergraduate student in the Electronics Engineering program at the University of St. La Salle (USLS) in Bacolod City, Philippines.

He has been an Undergraduate Research Assistant with the Tan Research Group in USLS since 2018. His research interests include biomedical signal processing, medical imaging, and deep learning.

Mr. Fermin is currently a student member of the Institute of Mathematics and its Application (United Kingdom). 


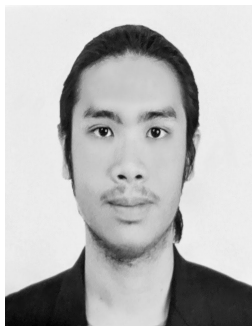

Myles Joshua T. Tan (M'20) was born in Bacolod City, Philippines in 1996. He received a B.S. degree in Biomedical Engineering, summa cum laude, from the University at Buffalo, the State University of New York in 2017 and an M.S. degree in Applied Biomedical Engineering from the Johns Hopkins University, Baltimore MD in 2018.

He has been an Assistant Professor of Chemical Engineering at the University of St. La Salle (USLS) since 2018. In 2020, he was appointed as an Assistant Professor of Natural Sciences in the same university. He has been actively involved in the education and training of students in the Departments of Electronics Engineering and Electrical Engineering at USLS. He also leads the Tan Research Group. His research interests include biomedical signal processing, medical imaging, deep learning, and engineering and mathematics education.

Asst. Prof. Tan is also a member of the Institute of Physics (United Kingdom), Tau Beta Pi - The Engineering Honor Society (USA), and an associate member of the Institute of Mathematics and its Application (United Kingdom). He is a recipient of the Tau Beta Pi Engineering Honor Society Record Scholarship and the Grace Capen award. 